\title{
ENTREVISTA A ANTONIO SKÁRMETA
}

\author{
Marcela Rosas Lira \\ Universidad de Chile \\ Santiago de Chile, Chile \\ marcelitarosas@hotmail.com
}

Antonio Skármeta Vranicic (1940) es escritor y académico, Premio Nacional de Literatura en 2014. Estudió Filosofía en la Facultad de Filosofía y Educación de la Universidad de Chile, para posteriormente realizar estudios de posgrado en la Universidad de Columbia, Nueva York. Junto a la producción de una prolífica obra literaria, ha realizado labores de docencia universitaria, impartido talleres literarios e incursionado en el cine y la televisión, además de ejercer cargos diplomáticos.

Durante el año 1970, Antonio Skármeta se desempeña como docente del Departamento de Español de la Universidad de Chile, al tiempo que participa activamente como intelectual de izquierda en iniciativas culturales afines al gobierno de Salvador Allende. Como parte del Departamento de Español, publica algunos artículos en los primeros números de la $R C h L$ centrados fundamentalmente en el análisis de obras dramáticas chilenas ${ }^{1}$.

Al ser partícipe del momento fundacional de la $R C h L$, el escritor y crítico no solo vive de cerca los primeros años de esta publicación, sino que, además, es parte activa de los debates en torno a la cultura y al rol de los intelectuales suscitados durante el gobierno de la Unidad Popular. La entrevista que se presenta a continuación se sitúa en el momento en que, junto a su labor académica y a la publicación de artículos en la $R C h L$, Antonio Skármeta participa en la realización de talleres literarios y en la creación de revistas culturales como La Quinta Rueda ${ }^{2}$, instancias a través de las cuales se configura

Antonio Skármeta publica el artículo "El motivo de oposición entre aldea y cuidad en dos dramas chilenos" (en relación a los dramas Pueblecito de Armando Moock y La canción rota de Antonio Acevedo Hernández) durante 1970 en el Número 1 de la $R C h L$ y “La burguesía invadida: I. Egon Wolff" en el Número 4 durante 1971.

2 La revista cultural La Quinta Rueda, cuyo título surge en directa alusión al rol secundario con que se percibe la cultura en relación a la preponderancia de otros factores en el proyecto revolucionario chileno, aparece durante 1972 al alero de la Editora Nacional Quimantú a pesar de tener una mirada crítica frente al proyecto cultural de Unidad Popular. 
un campo cultural marcado por la diversidad de puntos de vista frente a la coyuntura político-social chilena y al rol de la cultura en este contexto.

M. R. Lo primero que me gustaría preguntarle tiene ver con el programa de gobierno de Salvador Allende, en el cual la cultura es vista como un agente revolucionario, como algo que se debe masificar para facilitar la vía de acceso al socialismo, con lo cual se entiende que el programa allendista apostó por la masificación de la cultura desde todo punto de vista, como, por ejemplo, con Quimantú. Dentro de esa coyuntura aparece un grupo de intelectuales y artistas, entre los que está usted, los que, si bien son de izquierda y apoyan al gobierno de Salvador Allende, plantean algunos debates culturales que tienen que ver con su verdadero rol. Lo que se plantea fundamentalmente es el rechazo a esta mirada marxista más ortodoxa, tal vez, donde la cultura es el mero reflejo de la política y la economía. Este grupo de intelectuales del que usted formaba parte, que era el Taller de escritores de Chile, sacaron una declaración en una revista que se llamaba Cormorán que dirigía Enrique Lihn ${ }^{3}$, donde, si bien manifiestan su adhesión al proyecto de la Unidad Popular, plantean que antes de masificar la cultura, de hacer programas como el Quimantú para todos y todo aquello, había que crear conciencia, había que disminuir brechas educativas, que en Chile la educación no era lo mismo que en Cuba, etc. ¿Cuál es su recuerdo y sus impresiones de aquello?

A. S. Sí, el cambio de gobierno que hubo en la época, claro que sí influyó grandemente en la reflexión que hicieron los artistas, intelectuales, acerca de si ellos podían cumplir alguna función o podían ser parte de este proceso y cómo podrían hacerlo. Recuerdo que hubo varias instancias, lo que no recuerdo es cuáles son los años y las fechas...Recuerdo que fue muy, muy vivaz, por la manera cómo nos vinculábamos y el espíritu que lo animó, un taller de escritores que hubo, se llamó Taller de escritores de la Universidad Católica en un tiempo que era director de la Escuela de Periodismo de la Universidad Católica, el escritor Luis Domínguez. Entonces Luis Domínguez participó, creó este taller de escritores que dependía, las sesiones tenían lugar en la Universidad Católica. Había otro taller que funcionaba en donde está la casa central de la Universidad de Chile, a un costado estaba la librería de la Universidad de Chile y a un costado había una salita, donde también funcionaba otro taller que era Taller de escritores de la Universidad de Chile.

3 La revista Cormorán es creada bajo el auspicio de la Editorial Universitaria, comenzando en agosto de 1969 y terminando en 1970, periodo en que se erigió como un claro portavoz de las posturas de intelectuales de izquierda ligados al ámbito universitario. En su último número, aparece el documento "Por la creación de una cultura popular y nacional" elaborado por el Taller de Escritores de Chile, en el cual un grupo de intelectuales, entre los que se cuenta Antonio Skármeta, expresa su postura respecto a las políticas culturales del gobierno de Salvador Allende, haciendo frente a las concepciones que entienden la cultura como un reflejo pasivo del proceso revolucionario y delimitando el rol que tienen los artistas e intelectuales dentro de este proceso. 
Entonces todo esto, la idea de los talleres de literatura y que hubiera, que se enseñara la creación literaria a gente que quería expresarse y que los intelectuales asumíamos que esa gente necesitaba una ayuda, un impulso para expresarse, técnicas de expresión, estaba muy regada entre esta generación de escritores que pensaba que podíamos echar una mano en eso. Ahora, claro, podría ser una mirada un poquito paternalista también y, efectivamente, es un tipo de crítica que podríamos hacernos. Pero, al mismo tiempo, sentíamos que dentro de la actividad política que había entonces, había curiosidad, que no solamente los agentes políticos que eran el pueblo organizado, el sindicato, poblaciones, etc., no solamente hacían su trabajo político, sino que también tenían un ansia de expresar. Había una cierta, una cierta imagen como de que lo que estaban haciendo era algo que tenía un carácter épico. Tal vez por la misma idea flotante en el ambiente de que había habido una revolución violenta en Cuba y que esta era una revolución pacífica, pero que había fuerza y que era la hora de que el pueblo se pudiera expresar.

Todo esto era muy verdadero, entonces esto tenía manifestaciones públicas, manifestación pública mayor a la cual apeló muchas veces el gobierno de la Unidad Popular para sentar presencia y desalentar a los opositores que fueran más violentos. Era la expresión de masas, masas que marchaban, masas que cantaban, masas que decían "estamos acá protegiendo a nuestro gobierno", eso estaba muy, muy marcado, dentro de la conducta que tenía la gente en ese momento y que también permeó a los intelectuales. Esa es la situación anímica en la cual surgen los talleres literarios, por un lado, como un trabajo de expresión de los intelectuales, del grupo reducido de escritores, creadores ya aceptados digamos y, por otro lado, estaba el "bichito" de cómo llevar la expresión hacia la gente.

M. R. Usted fundó una revista en ese momento que se llamaba La Quinta Rueda, una revista que, incluso estando al alero de la propia Quimantú, fue una publicación bastante crítica con la falta de políticas más orgánicas por parte del gobierno. De ahí que el nombre La Quinta Rueda tenía que ver con esta idea de que la cultura era la "quinta rueda del carro”, el quedarse atrás. ¿Por qué fundar revistas?, o sea, por este mismo espíritu épico "formamos revistas, hacemos revistas, declaramos a través de las revistas, incidimos a través de las revistas" ¿este "boom" de las revistas tiene que ver con este mismo clima que ahora usted está describiendo?

A. S. Por cierto, era completamente inevitable que una editorial de la magnitud de Quimantú, que era una editorial estatal, es decir, no hiciera un aporte con una revista cultural. Inmediatamente todos los que éramos partidarios del gobierno de Allende, simpatizantes de la Unidad Popular, inmediatamente dijimos "tiene que haber una revista, una revista y una revista literaria”. ¿Qué carácter iba a tener esa revista literaria? Fue, fue una discusión, fueron discusiones informales de todo tipo, pero lo importante aquí fue la decisión de la Editorial Quimantú que sí era una editorial del Estado, de decir "sí, vamos a hacer una revista cultural". 


\section{R. y que duró pocos años '72 o '71-'72.}

A. S. Yo creo que tiene que haber durado lo que duró el gobierno de la Unidad Popular, creo que no se acabó porque se acabó la revista, porque la revista no tenía ya más vida, sino que se acabó por circunstancias externas.

M. R. Y los intelectuales de esa época ¿cómo imaginaron a un Chile socialista? ¿Cuál era el imaginario de esta vía chilena al socialismo? ¿Pensaron en un socialismo latinoamericano más desvinculado de la Unión Soviética? ¿Hubo un imaginario al respecto?

\section{A.S. No recuerdo que hubiera unanimidad sobre eso.}

M. R. Lo cual es propio de la época.

A.S. No, no había unanimidad. Había unanimidad sí en el apoyo al gobierno del presidente Allende y el gobierno del presidente Allende, hay que recordarlo, era una coalición de partidos que lo apoyaban, más una masa muy grande de independientes, si sumabas los votos de los partidarios no se llegaba a ese apoyo que llegó a tener la Unidad Popular que, entre paréntesis, andaba por ahí por la mitad de los votos contabilizados que se podía haber, era un apoyo de una relativa mayoría.

Ahora, dentro de los talleres, había como dos talleres, un taller que se llamaba Taller de escritores de la Unidad Popular y estaba el Taller de escritores de la Universidad Católica... este grupo de escritores era heterogéneo, recuerdo la frase de un escritor. En una discusión dijimos: "bueno, aquí lo que hay que hacer, lo que tenemos que hacer es que nosotros los intelectuales tenemos que apoyar la revolución" y recuerdo que este escritor preguntó: “¿no será primero que hay que hacer una revolución para apoyarla después?”.

Ahora, había algunas influencias un poco de ambiente, de Cuba. Cuba era un referente para muchos. Cuba tenía una política cultural muy visible que era Casa de las Américas. Casa de las Américas era una organización que publicaba cantidad de libros, clásicos latinoamericanos, tenía un premio que era importante en la época, tenía nuevas revistas y toda la cosa. Pero, mira, estos cubanos hicieron la revolución, tienen la Casa de las Américas que organiza esto y lo otro, este era un modelo que había en la mente de algunos.

Había otros que pensaban que la cultura tenía que batírselas "con sus propias alitas y patitas" y que los gobiernos y los Estados no tenían que tener ninguna injerencia en esto y no tenía por qué dedicarse a fomentar ninguna cosa en especial. Que uno podía apoyar a un régimen, pero que todas las intervenciones que había en la historia de la cultura terminaban con una manipulación de los intelectuales y, por lo tanto, no había mucho entusiasmo por ver una acción concertada del gobierno para apoyar la cultura. Este era un debate generalizado y los talleres de escritores que se forjaron a la larga no se hicieron mucho cargo más de este debate porque se transformó en lo que tenía que ser, un taller literario en que la gente discutía textos literarios, hablaba de literatura y algún texto a lo mejor tenía que ver con la inmediatez política, muy poco, cada uno seguía con su "rollo" a veces matizado por lo que estaba pasando, pero no era como que 
el proceso de la Unidad Popular hubiera tocado muy fuertemente a la totalidad o a la gran mayoría de los intelectuales. Estaban preocupados, votaban por la Unidad Popular probablemente, la apoyaban, pero no salió de allí algo que ni remotamente se acercara a una suerte de literatura militante.

M. R. Sin duda, lo que más llama la atención al ponerse a reconstruir el momento histórico y cultural es encontrarse con un montón de debates y posturas.

A.S. Debate, es que esa es la palabra exacta, durante todo el tiempo se pasó en un debate y las revistas que salieron, bueno, digamos la revista más expresiva de esto fue La Quinta Rueda que es un debate permanente ya en el mismo consejo de redacción, ni hablar de los aportes que iba haciendo cada uno de cómo tenía que ser la revista, esa revista no acabó de tener una personalidad cuando vino el golpe y se terminó. Y la $R C h L$ al ser una revista universitaria y al estar representada en ella gente de distintas opiniones y tendencias políticas, también había gente que no era de la Unidad Popular. Entonces esa revista mantuvo, yo diría que mantuvo un estatus académico "salpicado" por la inmediatez, pero "salpicado", aunque yo creo que tuvo siempre un nivel académico.

M.R. Yendo ya a la RChL, en el discurso de presentación de la revista se señala que la revista responde a temas que se plantearon en la Reforma Universitaria, sobre todo temas que tienen que ver con profundizar la investigación, profundizar en la cultura nacional, dejar de ser meros transmisores de conocimientos traídos de afuera y generar conocimiento, generar investigación, difundir letras nacionales y latinoamericanas y que la RChL nace en ese espíritu.

A.S. Por eso se llama Revista Chilena de Literatura y no revista de literatura chilena. Esa fue la primera discusión que hubo, cómo se iba a llamar, hay un matiz bien distinto.

M. R. Es una revista que desde Chile se propone abordar autores y literatura chilena $y$ autores y literatura latinoamericana, o sea, fue una revista ciento por ciento latinoamericana. Y ahi publica usted dos artículos, publica en el año 70, en el número uno, un artículo sobre dos dramas chilenos, además usted es de los pocos autores que hace análisis de obra dramática. Después en el 71 sale su análisis sobre Los invasores. Leyendo los dos análisis, su enfoque es socio-histórico, usted habla de la contingencia chilena entremedio, usa categorías marxistas, habla de las clases conservadoras y de cómo infunden el miedo cuando se sienten amenazadas. ¿Estaba en usted la inquietud de hacer análisis socio-histórico o esta primera etapa tuvo un enfoque un metodológico más especifico? $O$ ¿había variedad?, porque en sus análisis está muy clara la continuidad de la obra con la contingencia que está viviendo usted en ese entonces.

A.S. Es que leíamos obras que no tenían que ver con la crítica literaria en algunas ocasiones. Podríamos estar leyendo y en nuestras críticas estar influenciados por 
Gramsci, por ejemplo, o por Albert Camus, que siendo un escritor notable era también un notable ensayista y ataríamos algunas de esas ideas. Era muy variado, yo diría que lo que determinaba la aproximación a un texto o a algún fenómeno cultural era, primero, la realidad misma que nos hablaba de una manera y la interpretación que hacíamos de esta realidad era una que teníamos que acomodar a nuestra espontaneidad, es decir, lo que sucedía en Chile era atípico, era atípico en muchos sentidos porque era un proceso que tenía características de ser un proceso revolucionario y, al mismo tiempo, no era exactamente un proceso revolucionario, sino que era un proceso democrático en donde partes distintas se habían puesto de acuerdo para lograr una mayoría y lograr algo. Y cómo se aproximaban los distintos actores a lo que estaba sucediendo y lo que se había prometido y lo que se hacía era lo que creaba el conflicto. Así que era muy sui generis, muy sui generis. Así que a nosotros no nos servía nada para explicarnos nada, teníamos que ir "galopando" en un terreno desconocido.

M. R. Y en ese "galopar" en un terreno desconocido ¿habia conciencia de "yo prefiero escribir ensayos a artículos cientificos, habia alguna directriz al respecto? o en este "galopar" no más tampoco había una conciencia de una revista académica.

A. S. Sí, la $R C h L$ era una revista académica, era una revista que publicaba el Instituto de Literatura Chilena. Ahora, en el directorio de esa revista, según recuerdo, había distintas opiniones políticas y había distintas personalidades y, la mayoritaria era la que estaba de acuerdo con el gobierno de la Unidad Popular, y que andaba dando vueltas la idea de que los intelectuales tenían la responsabilidad de hacerse cargo de los cambios, apoyar los procesos y todo esto que, visto a la distancia, creo que fuimos un poquito majaderos en eso. En vez de hacer algo creativo, realmente bueno, estuvimos dando vueltas. Y había quienes decían "pero, por qué no, nosotros tenemos una responsabilidad con la cultura chilena, con nuestra tradición, es decir, no tenemos por qué estar sometiendo unas disciplinas que son estrictamente académicas a los quehaceres, a las preocupaciones contingentes". Hubo esa discusión en forma clara y velada, de las dos formas.

M. R. Los análisis que aparecen después del 76 son análisis absolutamente distintos a la época en que usted escribió, son análisis formalistas, estructuralistas, semióticos.

\section{A.S. Del 70 al 73 era una "fiesta".}

M. R. Era una fiesta de diversidad, porque había artículos del profesor Goic sobre los tópicos en La Araucana, pero también teníamos artículos como los de Ariel Dorfman que eran más bien unos ensayos líricos como el de "El patas de perro", por ejemplo.

A.S. "El patas de perro no es tranquilidad para mañana", la frase de Alessandri, de su campaña presidencial era "Alessandri es tranquilidad para el mañana". 


\section{M.R. Por eso viene "El patas de perro no es tranquilidad para mañana".}

A.S. De ahí viene esa frase, tranquilidad para el mañana, justamente lo que no quería mi generación es que hubiera tranquilidad, queríamos alboroto y cambio.

M. $R$. En la presentación de la revista realizada por el profesor Goic se hace alusión a un movimiento renovador de la crítica literaria chilena "liderado" por el Departamento de Español de la Universidad de Chile y que la revista también pretende ser como una especie de eco de este movimiento renovador de la crítica ¿Había tal movimiento? ¿Se puede hablar de un movimiento renovador de la crítica?

A.S. No, yo diría que la generación del profesor Goic que era maestro de nosotros, era una generación mayor. Yo no estudié español, estudié filosofía en Chile y estudié literatura afuera en Columbia University. Los que estudiaron allí que fueron discípulos de Goic, fueron gente que se vinculó más bien a movimientos de izquierda y que tuvieron una participación activa. Goic siempre trató de mantener la independencia académica, que no sé, es decir, yo creo que consideraba la actitud que tenían algunos de nosotros como "delirante", éramos "delirantes", esa es la palabra que usaba, decía "esto es una cuestión delirante" y hay que decir que sí, que en algunos momentos nosotros confundíamos los deseos con la realidad de una manera estruendosa y, a pesar de que éramos intelectuales y formados y leídos, de repente el clima que había en el país, la desesperación, nos hacía parecer más líricos que analistas. Entonces, en ese sentido, su observación no era mala, pero, al mismo tiempo, es decir, había algo que era claro, que mi generación, que éramos docentes, investigadores, no éramos apáticos al momento histórico, el momento histórico, otra vez, permeaba todo, y también permeaba el modo de acercarse y buscábamos entonces apoyo en textos que fueran complementando nuestra aproximación.

La generación de Goic hizo un trabajo formidable, en la generación de Goic estaban otros profesores como Mario Fernández, estaba el profesor Villegas. Goic era una personalidad muy relevante que acuñaba mucha gente en su claridad expositiva, entonces eso era estructuralismo y era estructuralismo renovado, no era un estructuralismo convencional. Y eso se hablaba, todo el lenguaje, los motivos, los temas, los tópicos, mira esa cuestión se trabajaba con mucho sistema y esa fue una generación que formó muy bien a los jóvenes que educó y estos jóvenes que educó salieron luego a las escuelas secundarias con buenos análisis de literatura y se despegaron mucho los análisis literarios de las contingencias en ese sentido. Porque todo se veía como temas, como motivos... eran como sumas y restas intelectuales.

Ahora, mi generación, era una generación alborotada tocada por la contingencia, tocada por la calle y por la obsesión de meter la calle en la universidad y llevar la universidad a la calle. Entonces, ahí convivimos, convivió el profesor Goic, por ejemplo, y otros profesores, el profesor Villegas con gente como Carlos Santander, por ejemplo, que era un simpatizante comunista, Ariel Dorfman, que era un independiente de izquierda, yo mismo que sentía simpatía por el MAPU. Pero, bueno, en fin, era una convivencia que se expresaba en la diversidad, era Chile, una convivencia discutida, peleada, animosa, 
eso es todo lo que Chile perdió. Entonces yo creo que la $R C h L$ tiene que haber sido, no necesariamente en su carga política, pero tiene que haber sido una expresión de esto, de la inmensa variedad vigente.

M. R. ¿Hasta dónde cree usted que una revista especializada, académica, etc., se podría haber permeado o cuánto dialogaba con la época? ¿La revista en su variedad de enfoques, de análisis, de aparatos teóricos nos estaría hablando de ese Chile diverso?

A. S. Sí, pero la revista, probablemente la circulación de la revista, o lo que la revista le podía devolver a la sociedad que la estaba creando, nada, si era una revista, sea como sea, intelectual. Pero, sí en muchos sentidos era un poco la imagen de la literatura chilena y la observación de la literatura chilena o los que hacían los chilenos con la literatura para afuera. Entonces tenía su contacto en el breve tiempo que duró, con Argentina, con Colombia, con Cuba, con Uruguay y todo eso.

Yo creo que el lenguaje de la revista en la mayoría de sus artículos son lenguajes que pueden entender estudiantes, intelectuales. Ahora, ese tipo de revistas ni ahora, ni antes ni después son revistas para el público en general. Son revistas para lectores que tienen una vocación de curiosidad académica, científica, literaria, es ese nuestro espectro. Ahora, dentro de ese espectro había algunas mentes o algunas tendencias que tenían tan codificada la especialidad del discurso literario que hablaban nada más que en términos estrictamente crípticos para la gente. Pero era, yo creo, una revista animosa.

Ahora entre Subercaseaux y Dorfman había un abismo, te quiero decir nada más que no era homogénea esa izquierda que había ahí, era muy, muy diferente el lenguaje, la actitud, el pensamiento, en disciplina, en formación, era muy poco lo que podíamos encontrar en común. Lo que teníamos en común era el apoyo al gobierno de Allende.

M. R. En comparación con esa época ¿cuál es su percepción del rol de las revistas en la actualidad? Porque ahora hay una discusión entre "escribimos ensayos o hacemos papers", algunos señalan que los profesores solo se dedican a hacer papers y dicen algunos sentirse "esclavizados" en un formato y que no tienen la libertad que tenían antes, etc.

A.S. Lo que pasa es que las universidades ya se cerraron sobre sí mismas, son instituciones académicas y acuérdate que entonces las universidades, la gran tarea, la gran virtud que existía en ese momento era "salir hacia afuera", la universidad volcada hacia el mundo y el mundo entrando a la universidad, esa era la mirada.

\section{R. Que era el espíritu de la Reforma Universitaria.}

A.S. Era la dinámica que animaba a todas, la Universidad Católica también hizo una tremenda Reforma Universitaria, ni hablar de la Universidad Técnica, ni hablar de Concepción y la Chile. Todos estábamos en eso, no se sacudieron los cimientos, en realidad, es un lugar común, se mantuvo todo lo académico, pero la preocupación era cómo si la realidad está golpeando todos los días, está asediando por todas partes, cómo 
no estamos tomando también como profesionales una actitud frente a eso, si no de qué vale la vida, de qué vale la literatura, si la literatura no contiene vida y vida había, aunque después se consagre en la literatura, en el momento en que entra en la literatura es también contingencia y esa contingencia tiene un marco histórico. Esos eran pensamientos que pedían ser interpretados dentro de contextos históricos.

Claro las tendencias estructuralistas y post-estructuralistas eran más asépticas, es decir, hay una frase bien clara que viene del pensamiento de Husserl, de la fenomenología, que es poner la realidad "entre paréntesis".

M. R. Nada más simbólico que esto, por eso son los enfoques que vinieron después del 76 al 80, porque el Departamento de Español fue prácticamente desmantelado en el '73.

A.S. Yo creo que se autodesmanteló y después yo no sé qué pasó.

M.R. Después volvieron muchos de ustedes a hacer clases, pero ya en los 90. Bueno usted también reaparece en los 90 en el mundo televisivo con "El show de los libros". En fin, la vuelta de muchos de ustedes es otro episodio, otro capitulo de esta historia.

A.S. Claro, cómo al volver buscamos modos modernos de insertarnos en la realidad. 